\title{
Análise do Processo de Destituição do Poder Familiar à Luz do Estatuto da Criança e do Adolescente: os motivos e suas implicações
}

\section{nas famílias}

\author{
Analysis of the process of distribution of family power in the light of the statute of children and ado- \\ lescents: the reasons and their implications in families

\section{Thiago Rosa Assis de Oliveira} \\ Como citar esse artigo. OLIVIERA,

\section{Resumo}

T. R. A. Análise do Processo de

Destituição do Poder Familiar à Luz do Estatuto da Criança e do Adolescente: os motivos e suas implicações nas famílias. Mosaico - Revista Multidisciplinar de Humanidades, Vassouras, v. 12, n. 3, p. 73-80, set./dez. 2021.

Nota da Editora. Os artigos publicados na Revista Mosaico são de responsabilidade de seus autores. As informações neles contidas, bem como as opiniões emitidas, não representam pontos de vista da Universidade de Vassouras ou de suas Revistas.

A proposta deste trabalho surge, a partir, de uma inquietação quanto aos casos de acolhimento institucional e processos de destituição do poder familiar vivenciados diretamente na prática de atuação como um dos agentes do sistema garantidor de direitos (SGD) que é o conselho tutelar. Busca analisar estes processos, compreendendo suas etapas e motivações, bem como, refletir sobre a atuação de profissionais técnicos e do juiz perante as sentenças determinadas que influenciam diretamente na vida das famílias afetadas. Esta pesquisa explora as produções bibliográficas sobre o assunto, apresentando aspectos quantitativos e qualitativos ao analisar dados emitidos pelo Ministério Público do Estado do Rio de Janeiro (MPERJ) e o Conselho Nacional de Justiça (CNJ) sobre os casos de destituição do poder familiar, acolhimento institucional e adoção. Espera-se que ao final deste artigo, seja possível promover ao leitor uma análise crítica e reflexiva quanto ao número de acolhimentos institucional, a destituição do poder familiar, seus motivos e principalmente sobre as práticas engendradas na máquina pública do poder judiciário e assistencial que em alguns casos, criminalizam e culpabilizam as famílias pobres.

Palavras-chave: Destituição do poder familiar; Acolhimento Institucional; Adoção.

\begin{abstract}
The proposal of this paper comes from an uneasiness about the cases of institutional sheltering and the process of dismissal of family power experienced directly in the performance as one of the agents of the system said to guarantee those rights, the Guardianship Council. It seeks to analyze these processes, understanding its phases and motivations as well as think over the performance of the technical professionals and the judge towards the stated sentences that influence directly the lives of the affected families. This research explores the bibliographic outputs about the subject, presenting qualitatives and quantitative aspects when analyzing data issued by Rio de Janeiro's Public Ministry (Ministério Público do Estado do Rio de Janeiro MPERJ) and the National Justice Council (Conselho Nacional de Justiça - CNJ) about the cases of dismissal of family power, institutional sheltering and adoption. It is expected that at the end of this article it is going to be possible to promote the reader a critical and reflective analysis in terms of the number of institutional sheltering, the dismissal of family power, its causes and mainly the practices engineered in the public machine of judicial and assistance power that, in some cases, criminalize and blame the poor families.

Keywords: Dismissal of family power; Institutional Sheltering; Adoption.
\end{abstract}

\section{Introdução}

A ação de destituição do poder familiar é uma das medidas penais aplicáveis aos pais ou responsáveis em casos de abandono, agressão física ou maus tratos. A maioria dos casos de destituição do poder familiar é precedida do acolhimento institucional. Os dados emitidos pelo Ministério Público do Estado do Rio de Janeiro no Módulo Criança e Adolescente (MCA) em seus últimos censos enumeram a negligência, o abandono pelos pais e a situação de rua como os maiores motivos que justificam a medida do acolhimento.

A inquietação quanto aos processos de destituição do poder familiar, e a atuação das equipes do SGD como um todo, fomentou a produção do presente trabalho como proposta de reflexão sobre os conteúdos analisadores que serão elucidados.

Através da exploração bibliográfica das produções qualitativas e quantitavivas sobre o assunto, abordaremos as questões inerentes à destituição do poder familiar, apresentando os motivos litados como justificativas que embasam as decisões jurídicas, e refletindo, sobre a atuação dos profissionais que atuam neste processo de sentenciamento quanto à perda do poder familiar.

\section{O Poder familiar}

$\mathrm{O}$ conceito de poder familiar possui suas origens na Roma Antiga no termo pater famílias que significa

Afiliação do autor:

${ }^{1}$ Universidade Federal Rural do Rio de Janeiro, Seropédica, RJ, Brasil. 
pai de família e atribuía ao homem o mais elevado grau de poder sobre sua família. Era o exercício máximo, ilimitado e absoluto de autoridade concedido ao chefe da organização familiar. Toda a função familiar girava em torno dos interesses do pai e seu poder sobre seus membros designando um modelo patriarcal. Tal poder lhe dava o direito não apenas de correção moral e castigo físico em prol da construção das virtualidades e dos bons costumes, como o de vender o filho por determinado período caso a família estivesse em dificuldades financeiras, para depois, recuperá-lo, tendo assim, uma forma de sacrifício em prol dos demais. Além disto, se este filho causasse algum dano a alguém, o pai poderia entregá-lo à vítima como forma de compensação do prejuízo sofrido. Já a seleção eugênica lhe permitia também o direito de vida ou morte ao abandonar o filho considerado débil (MADALENO, 2018, p. 901).

Em história social da criança e da família, Philippe Ariés (1986) afirma que a partir do século XVIII com a evolução da família medieval em moderna, o modelo familiar centrado na figura do pai sofreu alterações até não mais ser encaixado de forma única e singular. Com a construção de novos arranjos familiares e a aceitação de famílias compostas por mulheres como chefes de seus lares, o que era entendido anteriormente como poder ilimitado e exclusivo da figura paterna, agora se estende a ambos os pais em atribuições de poder-dever. Surge então o termo poder familiar, como tradução do exercício de autoridade dos pais sobre os filhos de forma temporária até que estes alcancem a maioridade (CAMINHA, 2015).

Este exercício de poder familiar é visto de forma não apenas unilateral ao ser desempenhado tão somente pelos pais, mas, é atravessado pelas intervenções do Estado desde os códigos de menores de 1927 e 1979, a Constituição Federal de 1988 e atualmente, com o princípio da proteção integral à criança e ao adolescente com o advento do Estatuto da Criança e do Adolescente (ECA) em 1990 (BRASIL, 1990).

A partir de então, a criança deixa de ser vista como um bem ou objeto pertencente aos pais e passa a ter direitos dentro desta relação familiar recebendo cuidados básicos para seu desenvolvimento sadio, físico e emocional, cabendo aos pais, o desempenho desta função de proteção e cuidado integral (CAMINHA, 2015).

\section{A Destituição}

A ação de destituição do poder familiar é iniciada a partir do momento em que não é mais possível a permanência do filho (a) no seio de sua família natural ou extensa em decorrência de violência grave ou morte, por exemplo.

Constatada a impossibilidade de permanência ou manutenção do vínculo familiar, é iniciado um processo judicial dada à iniciativa do Ministério Público ou de quem tiver o interesse, de acordo com o artigo 155 do Estatuto da Criança e do Adolescente (BRASIL, 1990). $\mathrm{O}$ estatuto prevê também, que em casos graves onde há a necessidade de afastamento imediato da criança ou adolescente do agressor, o juiz competente poderá designar temporariamente uma pessoa como cuidadora da vítima até o julgamento definitivo.

Dias (2016, p. 796) afirma que a suspensão do direito familiar, antes de tudo, deve atender aos interesses do filho, e que esta é a penalização maior aplicada aos genitores mediante ao ato de infração de negligência ou omissão aos seus deveres inerentes como cuidadores, sendo uma medida imperativa e não facultativa, porém, dado o direito de defesa pela parte acusada. A autora faz a distinção da perda e a suspensão do poder familiar ao afirmar, que a primeira se caracteriza sob a sentença judicial como sanção, e a suspensão ou extinção, como aquela ocorrida pela morte dos genitores ou do filho, ou mesmo sua emancipação.

O artigo 129 do Estatuto da Criança e do Adolescente (BRASIL, 1990) traz a suspensão ou destituição do poder familiar como uma das medidas aplicáveis aos pais ou responsáveis em casos previstos no artigo 98 desta mesma lei:

Art. 98. As medidas de proteção à criança e ao adolescente são aplicáveis sempre que os direitos reconhecidos nesta Lei forem ameaçados ou violados: I - por ação ou omissão da sociedade ou do Estado; II - por falta, omissão ou abuso dos pais ou responsável; III - em razão de sua conduta. (BRASIL, 1990).

A prerrogativa da proteção integral contida nos novos moldes de assistência à infância e juventude pelo Estatuto promulgado em 1990, considera a criança e o adolescente como detentores de todos os direitos fundamentais inerentes à pessoa humana. Logo em seu artigo $4^{\circ}$ declara que é dever da família, da comunidade, da sociedade em geral e do poder público, garantir que sejam efetivados os direitos como saúde, alimentação, educação etc. Seguindo mais adiante busca garantir também a integridade física, psíquica e moral visando que nenhuma criança ou adolescente seja vítima de negligência, discriminação, exploração ou castigos físicos de diversas formas (BRASIL, 1990).

A legislação atribui, à família, o dever de garantia dos direitos dos filhos. Espera-se que esta seja o seio de onde se provê os cuidados necessários ao desenvolvimento físico, psíquico e emocional que toda pessoa precisa para seu amadurecimento. Mas nem sempre o ambiente familiar se apresenta como o mais saudável e propício à convivência do filho. Espera-se então, que a comunidade, a sociedade em que ele esteja inserido, ou mesmo o Estado, se porte como uma espécie de extensão destes laços familiares e possa dar suporte ao que necessita.

O ECA em seus artigos 21 e 22, afirma que 
ambos os pais ou responsáveis legais possuem direitos e deveres iguais perante os filhos. Considera também, que o poder familiar será exercido de igual modo pelo pai e pela mãe a menos que haja discordância de uma das partes, o que deverá ser resolvido judicialmente, caso necessário.

\section{A Negligência}

Dentre os diversos motivos que podem levar à perda do poder familiar está a negligência, um termo muito comum e utilizado de forma bem ampla, o que nos faz pensar na necessidade de uma discussão um pouco mais profunda de seu conceito, que ao circular livremente pelas ruas toma formas e se difunde no senso comum ao apontar práticas que se compreendem como faltosas, omissas e que causam danos.

Ao pesquisar o conceito de negligência, um dicionário atribui ao termo as seguintes definições: falta de cuidado, de aplicação, de interesse, de atenção, desmazelo, desleixo e displicência (DICIO, 2020).

Seu conceito também é discutido em várias áreas como a saúde, social e jurídica. No livro Psicologia Jurídica no Brasil, Gonçalves (2015, p. 37) afirma que: "o termo negligência designa as omissões dos pais ou de outros responsáveis - inclusive institucional - pela criança e pelo adolescente quando deixam de prover as necessidades básicas para seu desenvolvimento físico, emocional e social".

Se o conceito de negligência nos remete a ausência de provisão de suprimentos, entre outras necessidades que as crianças possuem, estamos falando, em grande parte, das famílias pobres que vivenciam momentos de escassez e dificuldades no dia a dia juntamente com seus filhos.

Gonçalves (2015) afirma que "a negligência se aproxima da pobreza e da desigualdade social". Ojeda (1996) nos aponta que é comum confundir a pobreza com a negligência em locais de extrema pobreza, e alerta para uma análise do contexto social em que a família está inserida. Se toda a estrutura familiar é afetada pela falta de recursos e não apenas os filhos são privados de acesso á cuidados básicos não podemos classificar como uma negligência familiar, mas sim, negligência social.

Para Nascimento (2011), com a emergência do ECA, a família pobre ganhou um novo status passando a ser chamada de família negligente, o que "justificaria" a intervenção do Estado e a continuidade da prática de retirar crianças e adolescentes de suas famílias. "Não se retira mais por pobreza, mas, se retira por negligência. E, são os pobres os considerados negligentes".

É preciso punir os indivíduos em desvios, no caso as famílias negligentes ou ditas em potencial. Não basta apenas ser negligente, mas a possibilidade de um dia vir a se tornar já se justifica uma atuação impositiva punitiva (NASCIMENTO, 2011).
A criminalização da pobreza toma forma e vez diante da lei ao ser embarcada no termo e no conceito de negligência. As famílias pobres, tidas como foras da lei, são apontadas como negligentes e por isto "necessitam" de punição (NASCIMENTO, 2011).

A mesma norma que institui o aceitável e formaliza padrões a serem seguidos, dá luz e visibilidade aos desviantes e inapropriados. Um ideal de cuidado e proteção é alimentado pela ordem social existente e todo aquele que não o segue passa a ser considerado um infrator (NASCIMENTO, 2011). Por isto, aqueles que fogem e destoam do que entendemos como algo correto e que deve ser seguido, são considerados os negligentes que serão alvos das mais variadas penalizações que as leis como o Estatuto da Criança e do Adolescente, entre outras, preveem. Como resultante temos a culpabilização e posteriormente a aplicação das medidas ditas protetivas como o acolhimento institucional e a destituição do poder familiar.

O esquema sintetizado abaixo mostra a estrutura judicializante da negligência apresentando em primeiro lugar a constituição do comportamento considerado como normal e aceitável seguido pela marginalização daqueles desviantes, e por isto, criminalizado pelas leis e sociedade. Ao final, vemos a punição deste comportamento com a aplicação da lei e suas sanções.

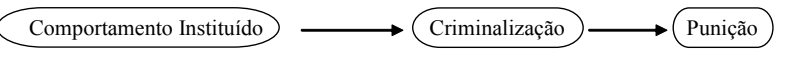

Figura 1. Estrutura Judicializante da Negligência.

Fonte: Oliveira; Silva (2019, p. 101).

O termo negligência é apresentando na literatura quase sempre atrelado a outro termo: o mau trato. Fato é, que existe a dificuldade para distinguir entre ambos, mas, podemos classificar a negligência como uma das diversas formas de maus tratos, assim como, a violência física, violência psicológica, abuso sexual, etc. Calheiros e Monteiro (2000, p. 153) afirmam que discutir o conceito de mau trato a partir da ideia de que este é uma imposição dos valores dos técnicos e das classes mais favorecidas às classes sociais menos privilegiadas ou aos grupos minoritários, representa uma forma simplista de equacionar esta questão.

Calheiros e Monteiro (2000,p.147/149) ao falarem sobre o mau trato e a negligência parental apresentam quatro definições: 1) médica: onde há a necessidade de se obter um diagnóstico baseado na ideia que o mau trato é sintoma de uma doença dos pais. 2) sociológica: surge como crítica a definição médica e tem como base central a noção de que o mau trato e a negligência implicam 
um contexto e um julgamento social dentro dos padrões da comunidade. 3) legal: busca estabelecer padrões nas relações parentais para atuação do tribunal. 4) jurídica: leis que ditam os deveres aos pais e responsáveis pela criança ou adolescente e permite a atuação do tribunal em caso de violações de direitos.

Fatores como: social, econômico, históricocultural, regionais e até mesmo subjetivos, podem influenciar no entendimento do conceito de negligência. Em certas sociedades, e em determinadas épocas pode se entender que alguns cuidados são mais apropriados que outros. Práticas de cunho educacional, disciplinares e com objetivos de socialização em determinadas culturas podem não ser bem aceitas por povos diferentes e serem vistas como maltratantes ou negligentes. O que dificulta ainda mais a definição homogênea do conceito.

A variação cultural que existe ao nível das crenças e das práticas educativas (GOODNOW; COLLINS, 1990) evidencia bem a não existência de normas universais sobre quais os cuidados que se devem ter com as crianças ou sobre o que pode constituir mau trato e negligência [...] (CALHEIROS; MONTEIRO, 2000, p.153).

Paiva et al. (2019, p. 1418) analisaram os motivos alegados para a reinstitucionalização em casas de acolhimento em Natal, no Rio Grande do Norte (RN), com base nas guias de acolhimento e desligamento disponibilizadas no Cadastro Nacional de Crianças e Adolescentes Acolhidos (CNCA) do Conselho Nacional de Justiça (CNJ, 2020) e apresentam uma realidade não muito diferente aos motivos informados no primeiro acolhimento. Segundo as autoras, a negligência configurou justificativa principal com $35,8 \%$ dos casos, seguida do abandono $(32,1 \%)$; dependência química dos pais ou responsáveis $(29,6 \%)$ e situação de rua $(29,6 \%)$.

\section{O Abandono}

Ao pensarmos na negligência e suas implicações diante do acolhimento podemos também abarcar o abandono pelos pais/responsáveis como uma das mais fortes e cruéis formas de negligenciar os cuidados perante seus filhos. $\mathrm{O}$ ato de abandonar é deixar a criança à própria sorte, desamparar, tendo esta, condições físicas e psicológicas de se cuidar ou não.

Deixar o filho em abandono é privar a prole da convivência familiar e dos cuidados inerentes aos pais de zelarem pela formação moral e material dos seus dependentes. É direito fundamental da criança e do adolescente usufruir da convivência familiar e comunitária, não merecendo ser abandonadomaterial,emocionalepsicologicamente, podendo ser privado do poder familiar o genitor que desampara moral e materialmente seu filho [...] (MADALENO, 2018, p.919).

Alves e Schulze (2019, p. 211) afirmam que "o abandono não se caracteriza apenas pela negligência física, mas também, pelo desamparo emocional e afetivo na relação pais-filho". Sendo assim, a compreensão da relação familiar estruturada no abandono pela ausência e falta, se configura na relação dos sujeitos que a vivenciam e seu ambiente, causando possíveis prejuízos físicos, emocionais e afetivos a todos.

\section{O Castigo Físico}

É possível pensar que existe na sociedade uma cultura de educação e correção dos filhos através do castigo físico. Por muito tempo se admitiu que os pais e responsáveis, bem como, os professores, utilizassem a correção física como maneira de educar e corrigir comportamentos inaceitáveis nas crianças. O castigo físico de forma imoderado era previsto na lei pelo Código Civil - Lei n ${ }^{\circ}$ 10406/2002 - (BRASIL, 2002) em seu artigo 1.638 inciso I, como uma das hipóteses para a perda do poder familiar.

Madaleno (2018) afirma que é inadmissível ao poder familiar a execução do castigo físico imoderado aos filhos, esta por sua vez, refere-se, por consequência, a admitir o castigo físico "moderado". Aplica-se o termo moderado entre aspas, na ideia de refletir sobre seu conceito e entendimento, uma vez que este passa pela configuração subjetiva de cada indivíduo, dando assim, diversos entendimentos quanto ao que é moderado, sendo impossível sua mensuração. O que permitiu a propagação desta cultura de educação pela correção física até os dias de hoje.

Atualmente a legislação impõe que tais práticas sejam criminalizadas e penalizadas. O ECA (BRASIL, 1990), que visa garantir a proteção integral da criança e do adolescente, traz no artigo 18 o dever de todos de velar pela dignidade destes excluindo-os de toda forma de tratamento desumano, degradante e violenta.

Art. 18-A. A criança e o adolescente têm o direito de ser educados e cuidados sem o uso de castigo físico ou de tratamento cruel ou degradante, como formas de correção, disciplina, educação ou qualquer outro pretexto, pelos pais, pelos integrantes da família ampliada, pelos responsáveis, pelos agentes públicos executores de medidas socioeducativas ou por qualquer pessoa encarregada de cuidar deles, tratá-los, educá-los ou protegê-los. Parágrafo único. Para os fins desta Lei, considera-se: I - castigo físico: ação de natureza disciplinar ou punitiva aplicada com o uso da força física sobre a criança ou o adolescente que resulte em: a) sofrimento físico; ou b) lesão; II - tratamento cruel ou degradante: conduta ou forma cruel de tratamento em relação à criança ou ao adolescente que: a) humilhe; 'ou b) ameace gravemente; ou c) ridicularize. (BRASIL, 1990).

A Lei da Palmada, é outra ferramenta importante dentro da atualidade que visa à proibição do castigo físico na educação dos filhos. $\mathrm{O}$ apelido foi dado à 
Lei $\mathrm{n}^{\mathrm{o}} 13.010$ (BRASIL, 2014) que alterou o artigo 18 do ECA e prevê que pais que maltratarem os filhos sejam encaminhados ao programa oficial de proteção à família e a cursos de orientação, tratamento psicológico ou psiquiátrico, além de receberem advertência. A criança que sofrer a agressão, por sua vez, deverá ser encaminhada a tratamento especializado. Também determina que profissionais da saúde, educação, assistência social e os demais agentes do sistema de proteção atuem de maneira preventiva, identificando evidências e diagnosticando possíveis agressões físicas sofridas, devendo obrigatoriamente comunicar ao conselho tutelar e demais autoridades locais.

\section{A Falta de recursos financeiros}

Vejamos o que diz no artigo 23 do ECA: A falta ou a carência de recursos materiais não constitui motivo suficiente para a perda ou a suspensão do pátrio poder familiar, expressão substituída pela Lei $\mathrm{n}^{\circ} 12.010$ de 2009 (BRASIL, 2009). Andrade (2016) do Ministério Público de Pernambuco ao comentar o artigo citado acima afirma que:

\begin{abstract}
Dos maiores avanços trazidos pelo bem-vindo Estatuto da Criança e do Adolescente, a regra do art. 23 enterrou de vez nos escombros da recente história deste País, o entulho autoritário representado pela combinação do art. 45 , I, com o art. $2^{\circ}$, I, "b", do revogado Código de Menores- Lei 6.697, de 10.10.79 - que permitia - e disso se fez uso e abuso, a título de proteção aos interesses do menor- a decretação da perda ou suspensão do pátrio poder na hipótese de os pais ou responsáveis estarem impossibilitados de prover as condições essenciais à subsistência, saúde e instrução obrigatória dos filhos menores (ANDRADE, 2016).
\end{abstract}

Ao analisar a situação familiar e verificada a carências dos recursos matérias e financeiros, o juiz deverá inseri-los em programas de auxílio, promoção e proteção para garantir a permanência dos vínculos familiares, uma vez que é dever também do Estado e não só da família e da sociedade garantir estes direitos. Porém, tal situação de insuficiência e falta de recursos não poderá servir de justificativa para que estas famílias abandonem seus filhos, expondo-os á situações de risco e vulnerabilidades, o que constituiria então, motivos para a perda do poder familiar (SOUZA, 2019, p. 205).

Pantuffi (2018, p. 56) ao analisar o perfil das famílias que sofrem o processo de destituição do poder familiar, afirma que "constatou-se que, em sua maioria, as famílias em questão viviam em uma situação de pobreza, com poucos ou nenhum acesso a direitos sociais". Aponta o baixo nível de escolarização, sendo a maioria, somente com o ensino fundamental concluído, exercendo atividades informais no mercado de trabalho e com baixa remuneração, situação de rua ou moradia em abrigos públicos, com dependência de álcool e outras drogas. Somente $9 \%$ das pessoas faziam parte de algum programa de apoio e proteção social, evidenciando assim, uma violação de direitos ainda maior, e a dificuldade de efetivação das políticas públicas de assistência voltada para esta população.

Diante dos fatos apresentados, podemos refletir ainda mais, sobre como a carência socioeconômica influencia direta e indiretamente ao longo da história, como determinante para o rompimento de vínculos familiares.

\section{O Crime}

Por fim, acrescentamos a hipótese de destituição em consequência de crime doloso cometido contra o filho ou outra pessoa, causando prejuízos à criança vítima, impossibilitando assim, o exercício do poder familiar, conforme alteração do $\S 2^{\circ}$ do artigo 23 do Estatuto da Criança e do Adolescente (BRASIL, 1990) através da Lei 13.715/2018 (BRASIL, 2018) que passou a ter a seguinte redação:

Art. $23 \S 2^{\circ}$ A condenação criminal do pai ou da mãe não implicará a destituição do poder familiar, exceto na hipótese de condenação por crime doloso sujeito à pena de reclusão contra outrem igualmente titular do mesmo poder familiar ou contra filho, filha ou outro descendente. (BRASIL, 1990; BRASIL, 2018).

Diante de tais situações apresentadas acima, em que se configuram as violações dos direitos ou mesmo situações de possível risco, uma das medidas passíveis de aplicação pela autoridade judicial, é o acolhimento institucional ou familiar, priorizando sempre atender o melhor interesse da criança ou adolescente, avaliando assim, um possível retorno ao convívio familiar originário, ou a colocação em família substituta em consequência da destituição do poder familiar (ALVES; SCHULZE, 2019, p. 214).

Nesse contexto apresentaremos abaixo um levantamento estatístico analisando o número de crianças e adolescentes acolhidos no estado do Rio de Janeiro com dados do Ministério Público e também dados nacionais pelo Conselho Nacional de Justiça.

\section{Os Dados Estatísticos}

O Ministério Público do Estado do Rio de Janeiro lançou em 31 de Dezembro de 2019 o seu $24^{\circ}$ censo da população infanto-juvenil acolhida no estado através do Módulo Criança e Adolescente (MCA). Ao todo, são 1.575 crianças e adolescentes em situação de acolhimento institucional ou familiar aguardando uma decisão judicial de reintegração familiar ou de destituição do poder familiar. Dentre as causas motivadoras temos em primeiro lugar a negligência como responsável por 551 crianças e adolescentes acolhidos. Seguindo adiante, abandono pelos pais ou responsáveis (137), situação de rua (129), abusos físicos ou psicológicos (81) abuso/ 
suspeita de abuso sexual (73), conflitos no ambiente familiar (35), reintegração aos genitores mal sucedida (30), guarda ou tutela para família extensa mal sucedida (29) e também carência de recursos materiais (27), entre outros. O levantamento aponta que o maior motivo para o desligamento destas crianças e adolescentes em situação de acolhimento é a reintegração aos genitores, seguido pela evasão, colocação em família substituta, guarda ou tutela para família extensa, além de adoção, entre outros (MINISTÉRIO PÚBLICO DO ESTADO DO RIO DE JANEIRO, 2019).

O censo mensura também a quantidade de processos de destituição do poder familiar, e do total dos 1575 acolhidos, $43,92 \%$, ou seja, 726 crianças e adolescentes podem ser destituída de suas famílias originárias. Em relação à adoção, 174 já estão aptos ao processo, sendo a grande parte com faixa etária entre os 12 e 18 anos de idade vivendo há mais de cinco anos no acolhimento.

O sistema Nacional de Adoção e Acolhimento (SNA) aponta em seu cadastro que há atualmente 34.157 crianças e adolescentes acolhidos e distribuídos em 3.259 instituições em todo território nacional, e que $8,4 \%$ (2.881) estão disponíveis para adoção (CONSELHO NACIONAL DE JUSTIÇA, 2020, p. 40).

Fávero (2014 apud Pantuffi, 2018, p. 56) apresenta um estudo realizado na cidade de São Paulo indicando que $69 \%$ dos processos de destituição do poder incidiam apenas sobre a mãe, $5 \%$ sobre o pai e $26 \%$ sobre ambos. Aponta, assim, uma problematização de gênero ao responsabilizar a mãe pelo cuidado dos filhos e naturalizar a ausência paterna.

\section{Os profissionais e o lugar do discurso}

Aqui, se faz necessário apresentar um pouco das práticas e enfrentamentos que permeiam os profissionais atuantes no setor jurídico, e analisar, quais seus efeitos.

Psicólogos e assistentes sociais fazem parte do quadro técnico invocado para auxiliar nas decisões dos juízes em todo o território nacional. Por uma dificuldade de se obter informações a nível nacional em relação ao quantitativo de profissionais atuantes, apresentaremos apenas informações referentes ao estado do Rio de Janeiro.

Segundo a Corregedoria Geral de Justiça do Estado do Rio de Janeiro (CGJRJ) nas últimas informações apresentadas em 2011, havia cerca de 236 psicólogos e 314 assistentes sociais distribuídos entre as comarcas no estado.

O $3^{\circ}$ Fórum de Psicólogos (a) do quadro de concursados do Tribunal de Justiça do Rio de Janeiro ocorrido em janeiro de 2018, buscou conhecer a realidade das condições de trabalho da categoria em virtude do número de aposentadorias e a crescente precarização do setor. Para isto, os responsáveis aplicaram questionários individuais com objetivo de mapear questões técnicas e ético-políticas enfrentadas no dia a dia de trabalho dimensionando o grau de satisfação ou insatisfação com a organização. Dentre as respostas mensuradas, a necessidade do aumento no número de profissionais devido a grande demanda de trabalho e a redução do quantitativo decorrente de aposentadorias e remoções, férias, afastamentos, o grande número de comarcas atendidas pela mesma equipe, entre outros problemas, evidenciam algumas das dificuldades destes profissionais, com perda da qualidade de trabalho (CORREGEDORIA GERAL DE JUSTIÇA DO ESTADO DO RIO DE JANEIRO, 2018).

O levantamento apontou ainda, que a precarização da rede de proteção foi apontada por $84,62 \%$ dos profissionais como o que mais dificulta sua prática, seguida de, demanda profissional elevada (73,08\%); carência de psicólogos $(73,08 \%)$; demandas irreais dos operadores do direito (50\%); falta de compreensão do trabalho pelos operadores do direito (42,31\%); espaço físico inadequado (57,69\%); ausência de acesso à internet $(38,46 \%)$; falta de infraestrutura $(34,62 \%)$, entre outros. Os organizadores informaram que era possível que fossem marcadas mais de uma opção no questionário, por isto, o somatório é superior a 100\% (CORREGEDORIA GERAL DE JUSTIÇA DO ESTADO DO RIO DE JANEIRO, 2018, p. 47).

\footnotetext{
"Há que se pensar os efeitos que a cobrança institucional por uma produtividade desenfreada, que a substituição de concursadas (os) por peritas (os) e que a não reposição de profissionais aposentadas (os), podem produzir a médio prazo, implicando, no limite, em prejuízos irreparáveis no funcionamento e qualidade do trabalho das equipes técnicas no TJRJ"(SANTOS et al., 2018, p. 49).
}

Sobre o lugar dos profissionais do Serviço Social no Judiciário, Fávero (2018) apresenta suas reflexões quanto ao crescimento das demandas direcionadas ao assistente social: "essas requisições são múltiplas, complexas e desafiadoras e revelam o avanço da judicialização de expressões da questão social" (FÁVERO, 2018, p. 51).

A autora questiona se "a regressão de direitos e a intensificação da judicialização das expressões da questão social" (FÁVERO, 2018, p. 52), influenciam o trabalho dos assistentes sociais, transformando-os em "gestores da barbárie" ao invés de produtores de práticas e ações de ressignificação da realidade histórico-social. Aponta para o manejo ético no atendimento das demandas oriundas do judiciário e de seus interesses, atentando para uma postura que corrobore com a democracia e a justiça social, ao passo, que esta instituição detém o poder de coerção, julgamento e responsabilização penal dos indivíduos.

São várias as áreas de atuação do Direito em que 
a Psicologia e o Serviço Social se fazem presentes na atualidade, e discorrer de maneira mais detalhada sobre as práticas profissionais em cada uma delas nos levaria a um material denso e complexo - o que não é nosso objetivo neste artigo. Sendo assim, trataremos abaixo, apenas uma das questões tão importantes que fomentam a vara da infância e da juventude para exemplificação.

A participação em inquirição no depoimento de crianças vítimas ou testemunhas de violência pelo denominado Depoimento sem Dano (DSD) tem sido alvo de diversos debates quanto à aplicação, a eficácia e as atribuições dos profissionais da psicologia e do serviço social neste método. O Conselho Federal de Psicologia (CFP) publicou a Resolução $n^{\circ}$ 10/2010 (CONSELHO FEDERAL DE PSICOLOGIA, 2010) onde regulamenta a escuta de crianças e adolescentes na situação de violência e veda ao psicólogo atuar como inquiridor.

Para Zotto e Mehl (2017), com ou sem o depoimento sem dano, é preciso se pensar qual abordagem é a mais apropriada na proteção da criança, evitando assim, que a mesma reviva o sofrimento anterior. Preconiza também, que as profissões envolvidas no processo exerçam suas atividades em conjunto ao promover o diálogo e respeito.

Fávero (2018) e Arantes (2016) afirmam que esta metodologia pode - no lugar de reduzir danos - provocar justamente a revitimização na busca pelas provas com a tentativa de criminalizar o suposto agressor, colocando de lado a proteção, sem dar espaço para o acolhimento e a escuta das crianças e adolescentes envolvidos.

\footnotetext{
“Crianças e adolescentes são expostos à vitimização secundária, produzida pela ineficiência no trato da questão, e à vitimização repetida, quando ocorre mais de um incidente delitivo, ou ação ineficiente do Estado, ao largo de um período determinado..." (FÁVERO, 2018, p. 55).
}

Arantes (2016, p. 47-50) afirma que é necessário dar a oportunidade da criança falar, se assim ela desejar, respeitando seu direito, mas, não como uma imposição colocando-a como responsável pela produção de prova judicial, e que a resolução do CFP - já mencionada aqui - veda ao psicólogo o ato de inquirir, "mas não o de acolher e escutar a criança e o adolescente, de acordo com sua formação profissional e Código de Ética".

Esta ética precisa estar pautada na construção de relações de um poder que compreende a realidade dos sujeitos e tenta transformá-la de alguma maneira. Neste sentido, Foucault (1996, p. 10) aponta as práticas de saberes como fruto de conjunto de construções verbais de frases e signos denominado discurso. Nele, os saberes científicos, políticos e sociais, etc., exercem suas forças e conferem certas modalidades de existências.

Essas relações de poder constituídas através do saber se oficializam nos discursos e produzem assim, outros saberes e outros poderes, sujeitando os indivíduos de maneira sutil e despercebida até que sejam totalmente aderidas subjetivamente. Assim elas se caracterizam e tomam formas nas relações parentais (pais e filhos), profissionais (empregado e empregador), sociais (vizinhos e amigos) através dos comportamentos, linguagens e valores éticos e morais da sociedade (BORDIN, 2014, p. 225).

Pantuffi (2018, p. 65) aponta para o cuidado da atuação de psicólogos e assistentes sociais, que através de seus discursos, contribuem para a produção e sustentação da culpabilização exclusiva de famílias pobres intituladas como incompetentes no trato de seus filhos, servindo de embasamento para o rompimento de vínculos.

\section{Conclusão}

A partir de uma posição atuante do sistema de assistência social, de garantia de direitos e próxima do judiciário, como o conselho tutelar, buscou-se apresentar a transição da configuração familiar, antes regida apenas pelo poder do homem e posteriormente de igual modo entre ambos os pais; os casos de destituição do poder familiar, sendo a negligência como uma analisador das forças exercidas principalmente sobre as famílias pobres; as condições de trabalho e as práticas vividas pelos profissionais que atuam junto ao judiciário.

Compreendemos então, que são as ações na prática do nosso saber científico - seja da Psicologia, do Serviço Social, do Direito, da Medicina, ou outros - que irão configurar nossas relações de saber-poder entre o conhecimento e a utilização deste, como controle social, normatização de padrões de comportamento e regulação dos indivíduos, ou então, que irão resignificar estes espaços e estas práticas de subjetivação e objetivação dos sujeitos, através de ferramentas como os equipamentos da assistência social e do poder judiciário.

\section{Referências}

ANDRADE, O. R de. ECA comentado, artigo 2, livro 1 - tema: Direitos; 2016, Promenino Fundação Telefônica. Disponível em: http:// fundacaotelefonica.org.br/promenino/trabalhoinfantil/promeninoecacomentario/eca-comentado-artigo-23livro-1-tema-direitos/. Acesso: 02 jun. 2020 .

ALVES, M. C.; SCHULZE, D. M. No limite do psíquico e do legal: a transgeracionalidade em processos de destituição do poder familiar. Opinión Jurídica, Facultad de Derecho de la Universidad de Medellín, 18 (36). Enero-Junio 2019. pp. 209-231. ISSN (en línea): 2248-4078. Disponível em: https://dialnet.unirioja.es/servlet/articulo? codigo $=7513025$. Acesso em 02 Jun. 2020.

ARANTES, E. É Suficiente Recorrer à Convenção da ONU Sobre os Direitos da Criança em Detrimento da Legislação Nacional? Notas a propósito do Projeto de Lei ${ }^{\circ}$ 3.792, de 2015. Revista EMERJ, Rio de Janeiro, v. 19, n. 76, p. 43-61, out.-dez., 2016. Disponível em: https://www.emerj.tjrj.jus.br/ revistaemerjonline/edicoes/revista76/revista76 43.pdf. Acesso em 10 Jun. 2020 .

ARIÉS, Philippe. História Social da Criança e da Família. $2^{a}$ edição, Rio de Janeiro: Guanabara, 1986, p. 225. Disponível em https://edisciplinas.usp. br/pluginfile.php/5525040/mod resource/content/2/ARI\%C3\%88S.\%20 
Hist $\%$ C3\%B3ria $\% 20$ social $\% 20$ da $\% 20$ crian $\%$ C3\%A7a $\% 20$ e $\% 20$ da $\% 20$ fam $\%$ C3\%ADlia_text.pdf. Acesso em 26 Jul. 2021.

BRASIL. Estatuto da Criança e do Adolescente. Brasília, 1990. Disponível em: http://www.planalto.gov.br/ccivil 03/leis/18069.htm. Acesso em 10 Ago. 2020.

BRASIL. Código Civil. Brasília, 2002. Disponível em: https://www2.senado. leg.br/bdsf/bitstream/handle/id/70327/C\%C3\%B3digo\%20Civil\%202\%20 ed.pdf. Acesso em 04 Ago. 2020.

BRASIL. Lei $\mathbf{n}^{\circ}$ 12.010/2009. Dispõe sobre adoção; altera as Leis nos 8.069, de 13 de julho de 1990 - Estatuto da Criança e do Adolescente, 8.560, de 29 de dezembro de 1992; revoga dispositivos da Lei no 10.406, de 10 de janeiro de 2002 - Código Civil, e da Consolidação das Leis do Trabalho - CLT, aprovada pelo Decreto-Lei no 5.452, de 1o de maio de 1943; e dá outras providências. Brasília, 2009. Disponível em: http://www.planalto.gov. br/ccivil_03/_ato2007-2010/2009/lei/112010.htm. Acesso em 07 Ago. 2020.

BRASIL. Lei $\mathbf{n}^{\mathbf{0}} \mathbf{1 3 . 0 1 0 / 2 0 1 4}$. Altera a Lei no 8.069, de 13 de julho de1990 (Estatuto da Criança e do Adolescente), para estabelecer o direito da criança e do adolescente de serem educados e cuidados sem o uso de castigos físicos ou de tratamento cruel ou degradante, e altera a Lei no 9.394 , de 20 de dezembro de 1996. Brasília, 2014. Disponível em: http://www.planalto.gov. br/ccivil_03/_ato2011-2014/2014/lei/113010.htm. Acesso em 05 Ago. 2020.

BRASIL. Lei $\mathbf{n}^{0}$ 13.715, de 2018. Altera o Decreto-Lei $\mathrm{n}^{\circ} 2.848$, de 7 de dezembro de 1940 (Código Penal), a Lei no 8.069, de 13 de julho de 1990 (Estatuto da Criança e do Adolescente), e a Lei ${ }^{\circ} 10.406$, de 10 de janeiro de 2002 (Código Civil), para dispor sobre hipóteses de perda do poder familiar pelo autor de determinados crimes contra outrem igualmente titular do mesmo poder familiar ou contra filho, filha ou outro descendente. Brasília, 2018. Disponível em: http:/www.planalto.gov.br/ccivil_03/_ato2015-2018/2018/ lei/L13715.htm. Acesso em 30 Jul. 2020.

BORDIN, T. M. O saber e o poder: a contribuição de michel foucault. Saberes, Natal RN, Universidade Federal do Rio Grande do Norte, v. 1, n. 10 , nov. 2014, p. 225-235. Disponível em: https://periodicos.ufrn.br/saberes/ article/view/5088/4925. Acesso em 16 Jul. 2020

CAlHEIROS, M.; MONTEIRO, M. B. Mau Trato e Negligência Parental Contributos para a Definição Social dos Conceitos. Sociologia, problemas e práticas, Instituto Universitário de Lisboa, n. 34, 2000, p. 145-176. Disponível em: https://repositorio.iscte-iul.pt/handle/10071/398. Acesso em 28 Jul. 2020.

CAMINHA, A. P. P. A perda Do Poder Familiar No Direito Brasileiro: Uma Análise Sistemática Da Legislação Vigente. Revista da Faculdade de Direito da UFRGS - no 33, p. 55-82, 2015. Disponível em: https://seer. ufrgs.br/revfacdir/article/view/69154. Acesso em 03 Ago. 2020.

CONSELHO NACIONAL DE JUSTIÇA. Diagnóstico sobre o sistema nacional de adoção e acolhimento. Brasília, 2020. Disponível em https://www.cnj.jus.br/wpcontent/uploads/2020/05/relat diagnosticoSNA2020_25052020.pdf. Acesso 03 Jun. 2020.

CORREGEDORIA GERAL DE JUSTIÇA DO ESTADO DO RIO DE JANEIRO. Rio de Janeiro, 2018. Subjetividade, ética e produtividade. Encontro dos Psicólogos do TJRJ/2018. Disponível em http://cgj.tjrj.jus. br/documents/1017893/1087820/Cartilha+Atividade+Etica+e+Produtividad e+ok.pdf/6f07b251-4442-65ef-01e7-55bdf5342788. Acesso: 16 Jun. 2020.

CONSELHO FEDERAL DE PSICOLOGIA. Resolução CFP nº 010/2010. Disponível em: http://site.cfp.org.br/wp-content/uploads/2010/07/ resolucao2010_010.pdf. Acesso: 16 jun. 2020.

DIAS, Maria Berenice. Manual de direito das famílias. 11. ed. [e-Book]. São Paulo: Editora Revista dos Tribunais, 2016

OliveIRA, T. R. A. de; SILVA, R. B. da. Práticas de Saber-Poder entre Pobreza e Negligência que se configuram na Institucionalização da Infância. Revista Mosaico; Universidade de Vassouras, v. 10, n. 2, Suplemento, p. 96104, Jul/Dez., 2019. Disponível em: http://editora.universidadedevassouras. edu.br/index.php/RM/article/view/1796. Acesso em 23 jun. 2020.

DICIO. Significado de Negligência. Dicionário On Line de Português. Disponível em: https://www.dicio.com.br/negligencia/. Acesso em: 25 jun. 2020 .

FÁVERO, E. Serviço Social no sociojurídico: requisições conservadoras e resistências na defesa de direitos. Serv. Soc. Soc., PUC-SP, São Paulo/ SP, n. 131, p. 51-74, jan./abr. 2018. Disponível em: https://www.scielo.br/j/ sssoc/a/3WRyj8WGgkLx7mG5k4K6tPP/abstract/?lang=pt. Acesso em 06 jun. 2020.

FOUCAULT, M. A ordem do discurso. 3. ed. São Paulo: Edições Loyola, 1996.

GONÇALVES, H. S. Pscicologia jurídica no brasil. 3. ed. Rio de Janeiro: NAU; 2015.

MADALENO, Rolf. Direito de família. 8. ed. rev., atual. e ampl. Rio de Janeiro: Forense, 2018. Acesso em https://acljur.org.br/wp-content/ uploads/2018/07/Direito-de-Fam\%C3\%ADlia-Rolf-Madaleno-2018.pdf. Acesso em 02 Jul. 2020.

MINISTÉRIO PÚBLICO DO ESTADO DO RIO DE JANEIRO - $\mathbf{2 4}^{\mathbf{0}}$ Censo da População Infantojuvenil Acolhida no Estado do Rio de Janeiro (31/12/2019). Disponível em: http://mca.mp.rj.gov.br/24o-censo/. Acesso em 07 Ago. 2020.

NASCIMENTO, M. L. Primeiro Colóquio Internacional Michel Foucault Publicado no site do youtube 8 Nov. 2011. Disponível em: https://www. youtube.com/watch?v=RtfZ0MX5Y0Y\&t=292s. Acesso:21 maio 2020.

OJEDA, L. B. Maltrato de niños y adolescentes: una perspectiva internacional. Salud y Sociedad. Bol. oficina sant. Panam. p. 123-37; 21 de Fev. 1996, Repositorio Institucional de la OPS - Política General. Disponível em: https://iris.paho.org/handle/10665.2/15447. Acesso em 02 Set.2020.

PAIVA, L. I. et al. Acolhimento Institucional: Famílias de origem e a reinstitucionalização. Rev. Direito Práx., Rio de Janeiro, v. 10, n.02, 2019 , p. 1405-1429, Editora Universidade do Estado do Rio de Janeiro. Disponível em: https://www.e-publicacoes.uerj.br/index.php/revistaceaju/article/ view/40414. Acesso em 10 Ago. 2020.

PANTUFFI, L. A. Destituição do poder familiar: saber e poder nas "engrenagens" da medida de (des)proteção. Dissertação de mestrado - Instituto de Psicologia, Universidade de São Paulo, São Paulo, 2018. Disponível em: https://www.teses.usp.br/teses/disponiveis/47/47131/tde20122018-103818/pt-br.php. Acesso em 10 Ago. 2020.

SANTOS, E. P. S. et al. Restituição da Pesquisa com Trabalhadores Psicólogos no TJRJ. Subjetividade, ética e produtividade. Encontro dos Psicólogos do TJRJ/2018. Disponível em http://cgj.tjrj.jus.br/ documents/1017893/1087820/Cartilha+Atividade+Etica+e+Produtividade+ ok.pdf/6f07b251-4442-65ef-01e7-55bdf5342788. Acesso em 16 de Jun. de 2020 .

SOUZA, N. M. N. Destituição do Poder Familiar à Luz dos Princípios do Direito das Famílias. Revista do Ministério Público do Estado do Rio de Janeiro $\mathrm{n}^{\circ}$ 71, p. 197-222, jan./mar. 2019. Disponível em: http://www.mprj. mp.br/documents/20184/1287128/Nathalia_Moreira_Nunes_de_Souza.pdf. Acesso em 23 Ago. 2020.

ZOTTO, A. R. D.; MEHL, T. G. O Depoimento Sem Dano e a Atuação do Psicólogo Jurídico. Revista de Iniciação Científica, Criciúma, v. 15, n. 2, p. 153-172, 2017 / ISSN 1678-7706, Ediunesc - Editorial Unesc. Disponível em: http://periodicos.unesc.net/iniciacaocientifica/article/view/3741. Acesso em 03 Set. 2020 